TITLE:

\title{
Enhanced carrier extraction from Ge quantum dots in Si solar cells under strong photoexcitation
}

\section{$\operatorname{AUTHOR}(\mathrm{S}):$}

Tayagaki, Takeshi; Usami, Noritaka; Pan, Wugen; Hoshi, Yusuke; Ooi, Kazufumi; Kanemitsu, Yoshihiko

\section{CITATION:}

Tayagaki, Takeshi ... [et al]. Enhanced carrier extraction from Ge quantum dots in Si solar cells under strong photoexcitation. Applied Physics Letters 2012, 101(13): 133905.

\section{ISSUE DATE:}

2012-09-27

URL:

http://hdl.handle.net/2433/159450

RIGHT:

(C) 2012 American Institute of Physics 


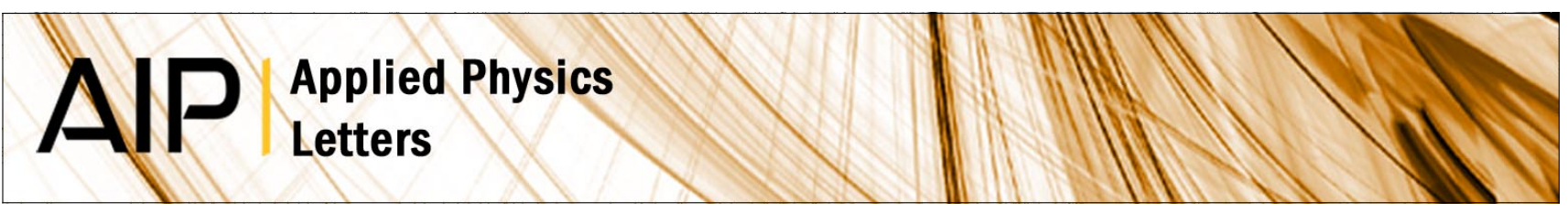

\section{Enhanced carrier extraction from Ge quantum dots in Si solar cells under strong photoexcitation}

Takeshi Tayagaki, Noritaka Usami, Wugen Pan, Yusuke Hoshi, Kazufumi Ooi et al.

Citation: Appl. Phys. Lett. 101, 133905 (2012); doi: 10.1063/1.4756895

View online: http://dx.doi.org/10.1063/1.4756895

View Table of Contents: http://apl.aip.org/resource/1/APPLAB/v101/i13

Published by the American Institute of Physics.

\section{Related Articles}

Front contact layer of multiphase silicon-carbon in thin film silicon solar cell

Appl. Phys. Lett. 101, 133910 (2012)

Limiting efficiencies of tandem solar cells consisting of III-V nanowire arrays on silicon

J. Appl. Phys. 112, 064321 (2012)

Dislocation-limited open circuit voltage in film crystal silicon solar cells

Appl. Phys. Lett. 101, 123510 (2012)

Influence of deep defects on device performance of thin-film polycrystalline silicon solar cells

Appl. Phys. Lett. 101, 123904 (2012)

Enhanced recovery of light-induced degradation on the micromorph solar cells by electric field

J. Appl. Phys. 112, 056104 (2012)

\section{Additional information on Appl. Phys. Lett.}

Journal Homepage: http://apl.aip.org/

Journal Information: http://apl.aip.org/about/about_the_journal

Top downloads: http://apl.aip.org/features/most_downloaded

Information for Authors: http://apl.aip.org/authors

\section{ADVERTISEMENT}
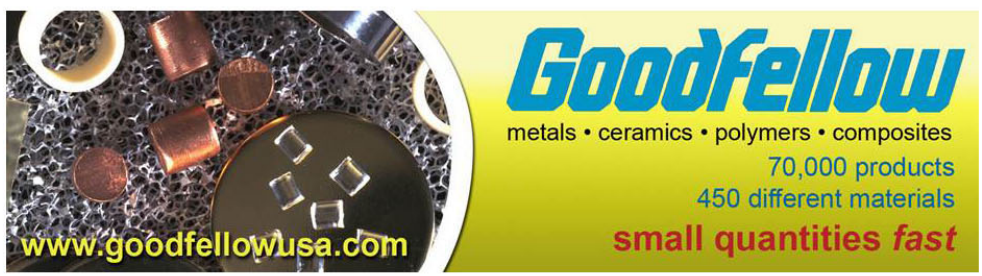


\title{
Enhanced carrier extraction from Ge quantum dots in Si solar cells under strong photoexcitation
}

\author{
Takeshi Tayagaki, ${ }^{1,2, a)}$ Noritaka Usami, ${ }^{3}$ Wugen Pan, ${ }^{3}$ Yusuke Hoshi, ${ }^{3}$ Kazufumi Ooi, ${ }^{1}$ \\ and Yoshihiko Kanemitsu ${ }^{1}$ \\ ${ }^{1}$ Institute for Chemical Research, Kyoto University, Uji, Kyoto 611-0011, Japan \\ ${ }^{2}$ PRESTO-JST, Kawaguchi, Saitama 332-0012, Japan \\ ${ }^{3}$ Institute for Materials Research, Tohoku University, Sendai 980-8577, Japan
}

(Received 23 July 2012; accepted 17 September 2012; published online 27 September 2012)

\begin{abstract}
We report studies of the carrier extraction mechanism in $\mathrm{Si}$ solar cells with Ge quantum dots (QDs), which enable the optical absorption of photons with energies below the band gap of the host. Photocurrent measurements revealed that the photocurrent in the QD solar cells increased superlinearly with increasing excitation intensity under strong photoexcitation, which differed greatly from the behavior of Si solar cells without Ge QDs. This nonlinear photocurrent generation indicates that the carrier extraction efficiency from QDs is enhanced under strong photoexcitation by nonlinear carrier extraction processes, such as two-step photon absorption and hot carrier generation via Auger recombination. (C) 2012 American Institute of Physics.

[http://dx.doi.org/10.1063/1.4756895]
\end{abstract}

Quantum dots (QDs) have attracted attention because of their interesting physical properties and potential applications in optoelectronic devices such as light emitters and solar cells. ${ }^{1}$ Solar cells using QDs, which enable the optical absorption of photons with energies below the band gap of the host, have recently been proposed and extensively studied. ${ }^{2-11}$ Many QD solar cells have been reported in attempts to demonstrate highly efficient solar cell devices. Thus far, all the reported experimental efficiencies of QD solar cells have been less than that of the best single-junction devices. Although increased short-circuit current density has been reported in devices with QDs, the open circuit voltage $\left(V_{\text {oc }}\right)$ has always decreased, which is related to the optical quality of the QD/bulk interface. ${ }^{4,6,8}$ Very recent work on $V_{\text {oc }}$ reduction has shown that suppression of thermal escape at low temperature results in voltage recovery. ${ }^{12}$ Thus, both suppressed thermal escape and enhanced carrier extraction from QDs are necessary to maintain the open circuit voltage and increase the current density. Therefore, understanding of the carrier dynamics, especially the carrier extraction mechanism from QDs, is one of the most critical needs in QD solar cell development.

As an alternative to carrier extraction by thermal escape, several mechanisms, such as two-step photon absorption ${ }^{13}$ and the Auger process, ${ }^{14}$ have been proposed to date. In twostep photon absorption, the first photon generates a carrier in a QD, and the second excites the carrier into a higher energy state following carrier extraction from the QD. ${ }^{13}$ In carrier extraction using Auger recombination, the carriers in the QDs are extracted by using the recombination energy between an electron-hole pair in Auger recombination. ${ }^{14}$

To study such nonlinear carrier extraction processes, here we used Ge dots in the intrinsic region of Si-based solar cells [Fig. 1(a) $] .{ }^{15-17} \mathrm{Ge} / \mathrm{Si}$ heterostructure provides a unique opportunity to investigate the fundamental physics of high-

\footnotetext{
${ }^{\text {a) }}$ Author to whom correspondence should be addressed. Electronic mail: tayagaki@scl.kyoto-u.ac.jp.
}

density carrier dynamics and carrier interactions in artificially controlled nanostructures. ${ }^{18-24}$ In Ge/Si QDs, a type II band offset is formed in which electrons and holes are spatially separated by the heterostructures, and holes, not electrons, are confined in the Ge QDs. Owing to the inherent indirect band gap nature of $\mathrm{Si}$ and $\mathrm{Ge}$ and the type II band alignment in $\mathrm{Ge} / \mathrm{Si}$ QDs, Ge QDs should exhibit a long carrier lifetime. ${ }^{25}$ In addition, hot carrier generation owing to Auger recombination has been reported in Ge/Si QDs. ${ }^{26}$ Therefore, the Ge/Si QD solar cell provides a chance to study systematically the carrier extraction mechanism from QDs under high carrier density. Although the external quantum efficiency $(\mathrm{EQE})$ in the near-infrared region reportedly increases when Ge QDs are stacked in multilayer structures, ${ }^{15}$ the mechanism of carrier extraction from Ge/Si QD solar cells has not been studied in detail.

In this letter, we report studies of the mechanism of carrier extraction in $\mathrm{Ge} / \mathrm{Si}$ QD solar cells using photocurrent measurements. We found that in these cells, the photocurrent increased superlinearly with increasing excitation power. This indicates that a nonlinear carrier extraction process such as two-step carrier generation via intermediate states or hot carrier generation owing to Auger recombination appeared under strong photoexcitation and caused the enhanced EQE in the QD solar cells. The nonlinear process allows carriers to be extracted without a reduction in the open circuit voltage, which is quite different from the wellknown thermal escape from QDs.

The samples were grown using a gas-source molecular beam epitaxy system (Air-Water VCE S2020) utilizing disilane and germane as the gas sources on p-type $\mathrm{Si}(100)$ substrates with a resistivity of $1-10 \Omega \mathrm{cm} .{ }^{27}$ Self-assembled Ge dots stacked in a 100-layer structure were separated by 39-nm-thick $\mathrm{Si}$ spacer layers and finally capped with a 50-nm-thick Si layer. The p-i-n junction was formed via thermal diffusion of phosphorous from a spin-coated diffusion source. The EQEs were measured at room temperature using a xenon lamp passed through a monochromator as a 
(a)

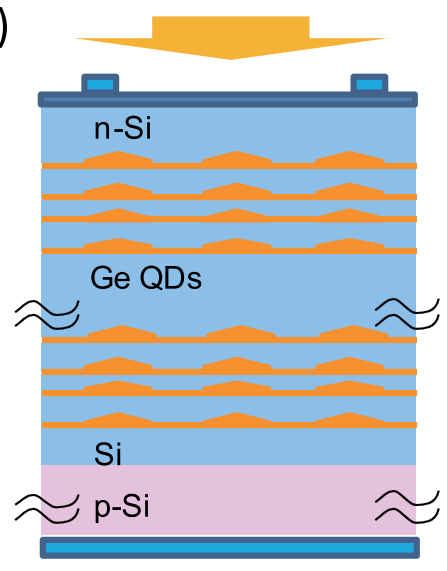

(b)

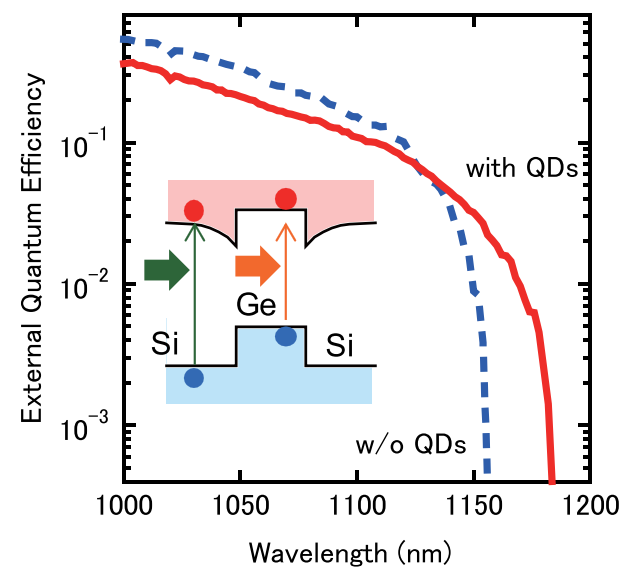

FIG. 1. (a) Schematic illustration of Si solar cell using Ge QDs. (b) External quantum efficiencies of Si solar cell with and without (w/o) Ge QDs. Inset: Schematic illustration of type II band offset in $\mathrm{Ge} / \mathrm{Si} \mathrm{QDs}$. light source or by lasers of several wavelengths. The short circuit (no bias) photocurrent was measured directly with a computer-interfaced Keithley 2636A source measurement unit. For strong photoexcitation, a cw laser was used as the excitation light source; the laser light was focused by using a lens with a focal length of $f=50 \mathrm{~mm}$.

Figure 1(b) shows the EQEs of the Ge/Si QD solar cells in the near-infrared region, which were measured using a xenon lamp. The EQE increased at longer wavelengths $(>1140 \mathrm{~nm})$, reflecting the fact that the Ge QDs cause additional photon absorption at longer wavelengths of the solar spectrum. As reported in our previous work, ${ }^{28}$ under weak photoexcitation, the EQE is independent of the excitation intensity; thus, the photocurrent was proportional to the excitation intensity.

Figure 2(a) shows the photocurrent as a function of the excitation intensity. The wavelength of the laser diode was $1310 \mathrm{~nm}$. Under high-density photoexcitation, the photocurrent shows a power-law dependence on the excitation intensity with an exponent of $\sim 1.1$. This superlinear dependence indicates that the carrier generation efficiency increases with increasing excitation intensity, which in turn suggests that
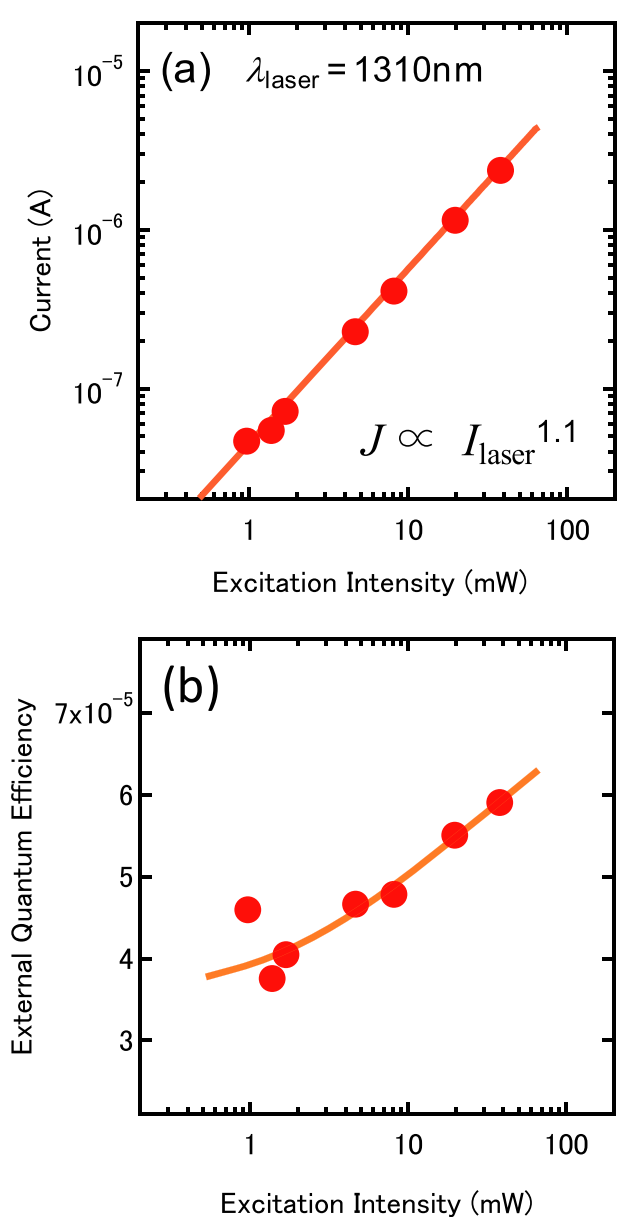
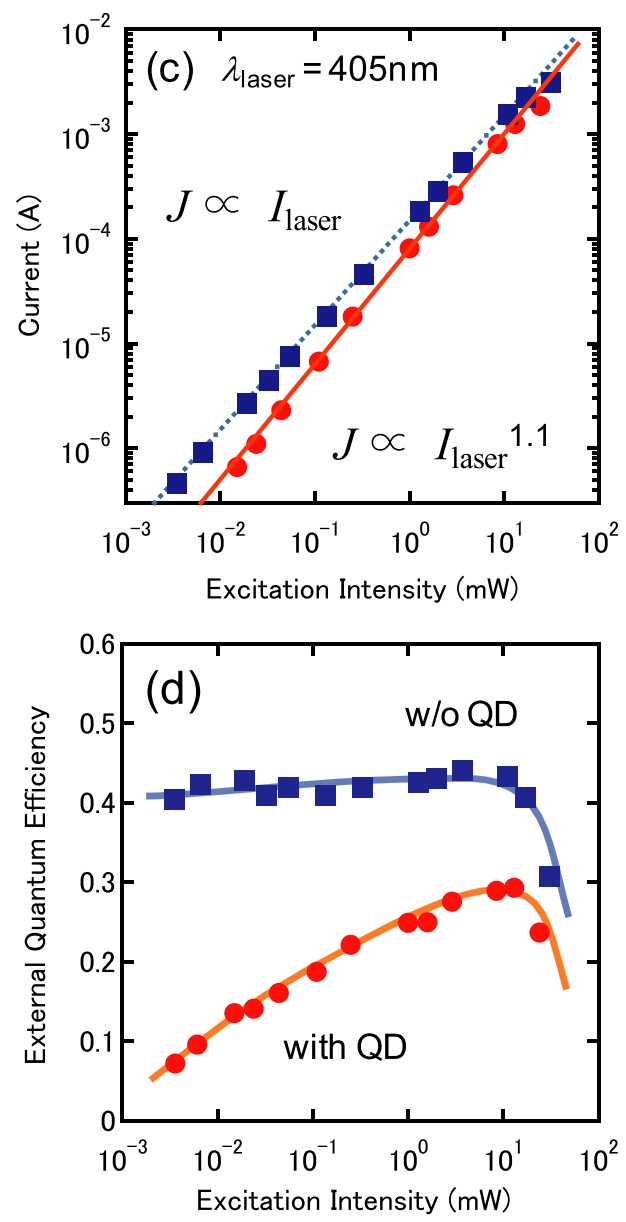

FIG. 2. (a) Photocurrent and (b) external quantum efficiency as a function of the excitation intensity $\left(\lambda_{\text {laser }}=1310 \mathrm{~nm}\right)$ in $\mathrm{Si}$ solar cell with Ge QDs. Solid line shows the power law dependence: $J \propto$ $I_{\text {laser }} 1.1$. (c) Photocurrent and (d) external quantum efficiency as functions of excitation intensity $\left(\lambda_{\text {laser }}=405 \mathrm{~nm}\right)$ in Si solar cells with and without (w/o) Ge QDs. Solid and dotted lines show the power law and linear dependences, respectively. 
the carrier extraction efficiency from QDs is enhanced under strong light irradiation. Figure 2(b) shows the EQE $\eta_{\text {ext }}$ obtained from the photocurrent divided by the excitation intensity: $\eta_{\text {ext }}=J / I_{\text {laser }}$. At the maximum excitation power of $\sim 40 \mathrm{~mW}$, the EQE increased to $\sim 6 \times 10^{-5}$, which is $20 \%$ larger than the value measured under weak photoexcitation. ${ }^{28}$

To clearly demonstrate the enhanced carrier extraction efficiency, we compared the Ge/Si QD solar cell to a Si solar cell without QDs under uv laser irradiation $\left(\lambda_{\text {laser }}=405 \mathrm{~nm}\right)$. The Ge QDs absorb the uv light, and high-density carriers are generated in them. Figure 2(c) shows the excitation intensity dependence of the photocurrent in the Si solar cells with and without Ge QDs. In the Ge/Si QD solar cell, the photocurrent increased superlinearly, like that under nearinfrared laser irradiation. In the Si solar cell without QDs, in contrast, the photocurrent increased almost linearly and began to saturate at the maximum excitation intensity. Figure 2(d) shows the EQE measured using the uv laser. Although the EQE increases with increasing excitation intensity in the $\mathrm{Ge} / \mathrm{Si} \mathrm{QD}$ solar cell, it is almost independent of the excitation intensity in the Si solar cell without QDs. At the maximum excitation intensity, the EQEs decreased in both solar cells. Thus, we concluded that the insertion of QDs into the Si solar cell causes this superlinear dependence of the photocurrent, enhancing the carrier extraction efficiency.

Figure 3(a) shows the EQE in the visible region under weak and strong photoexcitation, which were measured using a xenon lamp as a light source and by lasers of several wavelengths, respectively. Under weak photoexcitation, the EQE in the Ge/Si QD solar cell decreased at $\sim 350-700 \mathrm{~nm}$ compared with that of the Si solar cell without Ge QDs. This degradation of the EQE was caused by the strong photon absorption of Ge QDs in the uv and visible spectral regions. Owing to carrier confinement, sufficient carriers were not extracted from the Ge QDs; rather, carriers were recombined in the QDs or at the Ge/Si interfaces. The EQEs measured by using lasers with different wavelengths (532 and $635 \mathrm{~nm}$ ) also increased with increasing excitation intensity. The enhanced EQEs under strong photoexcitation are summarized in Fig. 3(a). The enhancement of the EQE under highdensity photoexcitation is more pronounced at shorter wavelengths, which is probably related to the strong photon absorption of Ge QDs occurring in the uv region. At shorter wavelengths, the optical absorption of Ge QDs becomes relatively strong, and the carriers are generated mainly in the Ge
QDs, not in the Si substrate. Therefore, the increased carrier density in Ge QDs makes nonlinear carrier extraction more pronounced. Because EQE enhancement was also observed in the near-infrared region, in which carriers are directly generated in the Ge QDs, it is related to the enhanced carrier extraction efficiency from QDs under strong photoexcitation. From these experimental results, we concluded that the extraction efficiency is enhanced under strong photoexcitation.

Finally, the photocurrent generation owing to nonlinear carrier extraction was clarified by using the photocurrent measurements under strong photoexcitation. In nonlinear carrier extraction, such as two-step photon absorption and hot carrier generation via Auger recombination [Fig. 3(b)], the photocurrent increased superlinearly with increasing excitation intensity, $J \propto I_{\text {light }}{ }^{\alpha}$, where $\alpha$ is greater than 1 . Thus far, two-step photon absorption has been studied using EQE measurements under additional near-infrared light irradiation $^{3,9}$ in which the carriers in QDs were primarily pumped out by thermal excitation, and the nonlinear escape processes were secondary. As noted in a recent paper, ${ }^{12}$ if the carriers are freely captured into and extracted from QDs, the separation between the quasi-Fermi levels of the valence/conduction bands and the confined electron/hole states will be diminished under thermal equilibrium. In this case, the band offset at the QD/bulk interface reduces $V_{\text {oc }}$ because the Fermi level of the valence/conduction bands coincides with that of the confined electron/hole state. When the thermal escape rate $\Gamma_{\text {thermal }}$ determines the carrier extraction efficiency from QDs, the photocurrent is proportional to the excitation intensity: $J \propto \Gamma_{\text {thermal }} I_{\text {light }}$. Thus, nonlinear photocurrent measurements would be a simple, useful method of confirming the appearance of the nonlinear carrier extraction process, which is expected to contribute to solar cell efficiencies beyond those of single-junction devices. Because only a subtle contribution from nonlinear carrier extraction was observed even under extremely strong photoexcitation, further enhancement of the mid-gap optical absorption would be necessary to realize highly efficient solar cells. The use of light management ${ }^{17}$ to increase the optical absorption at QDs would be a promising approach.

In summary, we studied the mechanism of carrier extraction in Ge/Si QD solar cells by using photocurrent measurements. Under strong photoexcitation, the photocurrent increased superlinearly with increasing excitation intensity, indicating that the EQE of the Ge/Si QD solar cell

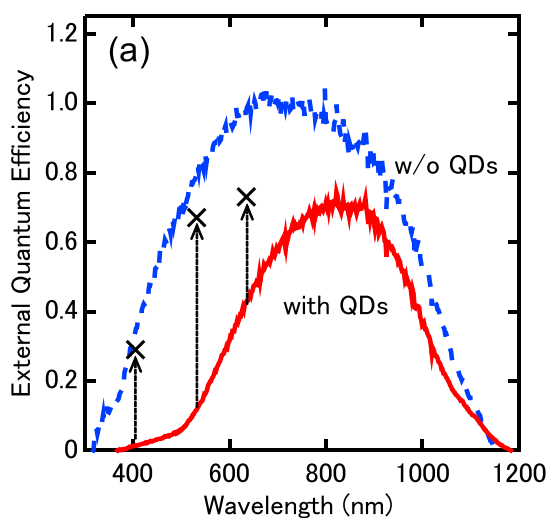

(b)

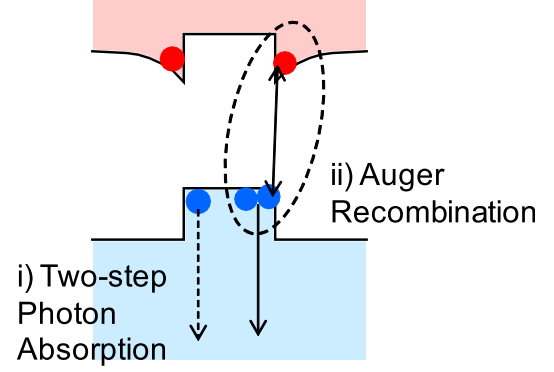

FIG. 3. (a) EQEs measured using a xenon lamp as functions of the optical wavelength in Si solar cells with and without (w/o) Ge QDs. Crosses: Maximum EQEs in the Ge/Si QD solar cell, evaluated by varying the excitation laser intensity. (b) Schematic illustration of nonlinear carrier extraction processes: (i) Two-step photon absorption. (ii) Hot carrier generation owing to Auger recombination. 
increased under strong photoexcitation. These findings indicate that a nonlinear carrier extraction mechanism, such as two-step photon absorption via an intermediate state or hot carrier generation owing to Auger recombination, appeared under strong photoexcitation, enhancing carrier extraction from the QD solar cells.

The authors thank N. Arifuku for his kind help with their experiments. This work was supported in part by the JST ALCA program and the Inter-University Cooperative Research Program of the Institute for Materials Research, Tohoku University. T.T. was supported by the JST PRESTO program and the Iketani Science Foundation.

${ }^{1}$ A. D. Yoffe, Adv. Phys. 50, 1 (2001).

${ }^{2}$ V. Aroutiounian, S. Petrosyan, A. Khachatryan, and K. Touryan, J. Appl. Phys. 89, 2268 (2001).

${ }^{3}$ A. Martí, E. Antolín, C. R. Stanley, C. D. Farmer, N. López, P. Dias, E. Cánovas, P. G. Linares, and A. Luque, Phys. Rev. Lett. 97, 247701 (2006).

${ }^{4}$ S. M. Hubbard, C. D. Cress, C. G. Bailey, R. P. Raffaelle, S. G. Bailey, and D. M. Wilt, Appl. Phys. Lett. 92, 123512 (2008).

${ }^{5}$ R. Oshima, A. Takata, and Y. Okada, Appl. Phys. Lett. 93, 083111 (2008).

${ }^{6}$ V. Popescu, G. Bester, M. C. Hanna, A. G. Norman, and A. Zunger, Phys. Rev. B 78, 205321 (2008).

${ }^{7}$ S. A. Blokhin, A. V. Sakharov, A. M. Nadtochy, A. S. Paiysov, M. V. Maximov, N. N. Ledentsov, A. R. Kovsh, S. S. Mikhrin, V. M. Lantratov, S. A. Mintairov, N. A. Kaluzhniy, and M. Z. Shvarts, Semiconductors 43, 514 (2009).

${ }^{8}$ D. Guimard, R. Morihara, D. Bordel, K. Tanabe, Y. Wakayama, M. Nishioka, and Y. Arakawa, Appl. Phys. Lett. 96, 203507 (2010).

${ }^{9}$ Y. Okada, T. Morioka, K. Yoshida, R. Oshima, Y. Shoji, T. Inoue, and T. Kita, J. Appl. Phys. 109, 024301 (2011).
${ }^{10}$ K. A. Sablon, J. W. Little, V. Mitin, A. Sergeev, N. Vagidov, and K. Reinhardt, Nano Lett. 11, 2311 (2011).

${ }^{11}$ K. Tanabe, D. Guimard, D. Bordel, and Y. Arakawa, Appl. Phys. Lett. 100, 193905 (2012)

${ }^{12}$ P. G. Linares, A. A. Martí, E. Antolín, C. D. Farmer, Í. Ramiro, and C. R. Stanley, Sol. Energy Mater. Sol. C 98, 240 (2012).

${ }^{13}$ A. Luque and A. Martí, Phys. Rev. Lett. 78, 5014 (1997).

${ }^{14}$ A. Luque, A. Martí, and L. Cuadra, IEEE Trans. Electron Devices 50, 447 (2003).

${ }^{15}$ A. Alguno, N. Usami, T. Ujihara, K. Fujiwara, G. Sazaki, K. Nakajima, and Y. Shiraki, Appl. Phys. Lett. 83, 1258 (2004).

${ }^{16}$ A. M. Kechiantz, L. M. Kocharyan, and H. M. Kechiyants, Nanotechnology 18, 405401 (2007).

${ }^{17}$ N. Usami, W. Pan, T. Tayagaki, S. T. Chu, J. Li, T. Feng, and T. Kiguchi, Nanotechnology 23, 185401 (2012).

${ }^{18}$ S. Fukatsu, H. Yoshida, N. Usami, A. Fujiwara, Y. Takahashi, Y. Shiraki, and R. Ito, Jpn. J. Appl. Phys., Part 2 31, L1319 (1992).

${ }^{19}$ P. Schittenhelm, M. Gail, J. Brunner, J. F. Nützel, and G. Abstreiter, Appl. Phys. Lett. 67, 1292 (1995).

${ }^{20}$ O. P. Pchelyakov, Yu. B. Bolkhovityanov, A. V. Dvurechensk $\breve{1}$, L. V. Sokolov, A. I. Nikiforov, A. I. Yakimov, and B. Voigtländer, Semiconductors 34, 1229 (2000).

${ }^{21}$ K. Brunner, Rep. Prog. Phys. 65, 27 (2002).

${ }^{22}$ A. I. Yakimov, A. V. Dvurechenskii, A. I. Nikiforov, A. A. Bloshkin, A. V. Nenashev, and V. A. Volodin, Phys. Rev. B 73, 115333 (2006).

${ }^{23}$ T. Tayagaki, S. Fukatsu, and Y. Kanemitsu, Phys. Rev. B 79, 041301(R) (2009).

${ }^{24}$ S. Miyamoto, O. Moutanabbir, T. Ishikawa, M. Eto, E. E. Haller, K. Sawano, Y. Shiraki, and K. M. Itoh, Phys. Rev. B 82, 073306 (2010).

${ }^{25}$ S. Fukatsu, H. Sunamura, Y. Shiraki, and S. Komiyama, Appl. Phys. Lett. 71, 258 (1997).

${ }^{26}$ T. Tayagaki, K. Ueda, S. Fukatsu, and Y. Kanemitsu, J. Phys. Soc. Jpn. 81, 064712 (2012)

${ }^{27}$ H. Sunamura, N. Usami, Y. Shiraki, and S. Fukatsu, Appl. Phys. Lett. 66, 3024 (1995)

${ }^{28}$ T. Tayagaki, N. Usami, and Y. Kanemitsu, "Influence of thermal annealing on the carrier extraction in Ge/Si quantum dot solar cells," Jpn. J. Appl. Phys. (in press). 